\title{
Revista Cerrados ISNN: 2448-2692
}

\section{Setor Sucroalcooleiro de Rio Brilhante (MS): Uma análise de Insumo-Produto}

\author{
Sugar Alcohol Sector in Rio Brilhante (MS): An Analysis input-output \\ Sector Azúcar y Alcohol Rio Brilhante (MS): Un Análisis del Producto \\ de Entrada
}

\author{
Tatiane Aparecida Dreger De Souza Fernandes \\ Universidade Estadual de Mato Grosso do Sul - UEMS, Campo Grande (MS), Brasil \\ fernandes.dreger@gmail.com \\ Mateus Boldrine Abrita (iD) \\ Universidade Estadual de Mato Grosso do Sul - UEMS, Campo Grande (MS), Brasil \\ mateusabrita@hotmail.com \\ Wesley Osvaldo Pradella Rodrigues \\ Universidade Federal de Mato Grosso do Sul - UFMS, Naviraí (MS), Brasil \\ wesley.rodrigues@ufms.br
}

\begin{abstract}
Resumo
Rio Brilhante, localizado no estado de Mato Grosso do Sul, vem se destacando na produção de cana de açúcar, sendo que no ano de 2017 foi a segunda maior produtora do Brasil. Neste sentido, pensar no conceito Região é entender que existem inúmeras diferenciações regionais, o que, consequentemente, coloca como necessária uma análise mais aprofundada. Não obstante, diversos teóricos tenham buscado, por meio do desenvolvimento regional, explicar essas complexidades encontradas em cada região de cada subespaço, entre eles destaca-se François Perroux, que permeou sua teoria a partir dos polos de crescimento. Assim, fundamentado nas ideias do autor, estabelecemos como objetivo deste trabalho analisar, por meio de uma matriz insumo-produto, se o setor sucroalcooleiro atua como um polo de crescimento no município de Rio Brilhante - MS. Para tanto, foi adotada uma análise de matriz insumo-produto que permite verificar quais setores possuem maior capacidade de gerar impactos na economia. No resultado das análises sobre o setor sucroalcooleiro de Rio Brilhante (MS), observamos indícios de que este atua como um setor chave para o crescimento econômico do município, entretanto não se pode afirmar que ele atua como um polo de crescimento no sentido estrito da teoria de Perroux.
\end{abstract}

Palavras-chave: Rio Brilhante (MS). Setor Sucroalcooleiro. Matriz de insumo-produto. Desenvolvimento Regional. Polos de Crescimento. 


\begin{abstract}
Rio Brilhante, located in Mato Grosso do Sul state, has been emerged in sugar cane production and the city was the second biggest producer in Brazil in 2017. In this way, thinking about region concept is to understand many regional differences, which demands a deeper analysis. However, many theorists tried to explain the complexities found in each region of each subspace by means of regional development, including François Perroux, who drove his theory according to growth poles. Based on the author's ideas, we established the objective of this work to analyze, through an input-product matrix, if the sugar and alcohol sector acts as a growth pole in the municipality of Rio Brilhante - MS. For that, an input-product matrix analysis was adopted that allows verifying which sectors have the greatest capacity to generate impacts on the economy. The analysis of sugar alcohol sector in Rio Brilhante (MS) indicates that the sector acts as a key sector for the economic growth. However, it cannot be said that it acts as a growth pole in the strict sense of Perroux's theory.
\end{abstract}

Keywords: Rio Brilhante (MS). Sugar Alcohol Sector. Input-Output Matrix. Regional Development. Growth Pole.

\title{
Resumen
}

Rio Brilhante, ubicado en el estado de Mato Grosso do Sul, se ha destacado en la producción de caña de azúcar, y en 2017 fue el segundo productor más grande de Brasil. En este sentido, pensar en el concepto de Región significa entender que existen innumerables diferenciaciones regionales, lo que, en consecuencia, requiere un análisis más profundo. Sin embargo, varios teóricos buscaron, a través del desarrollo regional, explicar estas complejidades encontradas en cada región de cada subespacio, entre ellos se destaca François Perroux, quien impregnó su teoría desde los polos de crecimiento. En este sentido, el objetivo de este trabajo fue verificar si el sector de azúcar y alcohol actúa como polo de crecimiento en lo municipio de Rio Brilhante-MS, para tal fin se adoptó un análisis de matriz insumo-producto que permita verificar qué sectores tienen mayor capacidad de generar impactos en la economía. Al analizar el sector azúcar-alcohol en Rio Brilhante (MS), hay indicios de que el sector actúa como un sector clave para el crecimiento económico del municipio. Sin embargo, no se puede decir que actúe como polo de crecimiento en el sentido estricto de la teoría de Perroux.

Palabras-clave: Rio Brilhante (MS). Sector azúcar y alcohol. Matriz de insumo-producto. Desarrollo regional. Polos de crecimiento.

\section{Introdução}

As desigualdades dentro do espaço geográfico trouxeram a necessidade dos estudos regionais, tendo em vista que essas disparidades foram cada vez mais evidentes principalmente com os processos de industrialização (SOUZA, 2005). Historicamente, as atenções voltadas para essas problemáticas regionais ganham proeminência em meados dos anos 50 do século $\mathrm{XX}$, oportunizando o surgimento de diversas teorias a respeito do Desenvolvimento Regional, inspiradas pelas ideias de Keynes, que têm como base o papel do Estado nos processos de desenvolvimento e crescimento nos momentos de crise. (BELLINGIERI, 2017) Estas teorias foram uma importante 
ferramenta principalmente nos países subdesenvolvidos, que tinham como ponto em comum identificar as diferenciações regionais e supri-las de acordo com cada região.

Todavia, julgamos necessário explicitar, em primeiro lugar, como os termos desenvolvimento e crescimento, estão sendo entendidos no contexto deste artigo. $\mathrm{O}$ desenvolvimento está relacionado às transformações econômicas, políticas e sociais, modificando as estruturas do padrão de vida da sociedade, tornando-se em algo qualitativo para população (BRESSER PEREIRA, 1968). Por sua vez, o crescimento econômico está ligado a mudanças quantitativas dentro da economia, tendo como objetivo o aumento da renda per capita e produtos globais. (MATTE JUNIOR, ALVES, 2017).

Considerados esses aspectos, ressaltamos um importante estudo que ganhou destaque nas análises de desenvolvimento regional que é a teoria dos Polos de Crescimento de François Perroux. O autor afirmava que o crescimento ocorria a partir de polos, tendo, como principal objeto, a indústria motriz ou um aglomerado delas, ao qual tinha uma forte identificação geográfica, onde produziam transformações dentro de cada região em que estava inserida (SOUZA, 2005). Esta teoria foi fundamental para os estudos regionais na compreensão dos processos de crescimento, sendo utilizada para movimentar os processos de crescimento dentro da região. (JESUS, SPINOLA, 2015)

No Brasil, os estudos de Perroux foram importantes principalmente nos anos 70 do século XX, em que o IBGE (Instituto Brasileiro de Geografia e Estatística) utilizou a teoria e, dessa forma, foi possível melhor definir concepções do conceito de região, isto é, as regiões "homogêneas", "polarizadas" e "regiões-programa". Estes estudos ajudaram nos estabelecimentos de indústrias em prol da promoção do crescimento de diferentes regiões no país. (JESUS, SPINOLA, 2015)

Alguns trabalhos valeram-se do arcabouço teórico de François Perroux para compreender a realidade brasileira contemporânea como, por exemplo, as análises feitas na Zona Franca de Manaus, região Norte do Brasil, em 2014. Na pesquisa, os autores articularam a teoria dos polos naquela região, e conseguiram identificar que as ideias de Perroux se enquadravam na implantação da ZFM (MARCHIORO, et al. 2014). Outro exemplo foi o caso do estado do Paraná, onde os autores evidenciaram os 
estabelecimentos de complexos industriais no estado, fomentando essas bases à teoria dos polos de crescimento e desenvolvimento (RIPPEL, LIMA, 2009). É possível constatar, portanto, que a teoria dos Polos de Crescimento de François Perroux tem se mostrado prospectiva para os estudos e pesquisas sobre o crescimento de uma determinada região geográfica.

Dessa perspectiva, neste artigo apresentamos o desenvolvimento de um estudo sobre o setor sucroalcooleiro da região de Rio Brilhante - MS situado em uma área estrategicamente situada no estado de Mato Grosso do Sul. Na década de 1930, o centro de produção de açúcar e álcool no Brasil, desenvolvia- se de forma preponderante na região nordeste. Contudo, muito por conta dos choques no preço do barril do petróleo na década de 1970, em meados do século XX, ocorre no país uma priorização na produção de cana-de-açúcar. Com os vários incentivos, as indústrias sucroalcooleiras se destacaram e atraíram investidores nessa área produtiva, o que oportunizou diversas instalações de usinas no país. Com suas largas extensões para plantio o estado de Mato Grosso Do Sul, localizado na região centro-oeste do país, ganhou evidência no estabelecimento de usinas na região, principalmente após o apoio do governo federal na primeira metade da década de 2000, para políticas de biocombustíveis e a disseminação da tecnologia flex. (BRITTS et al., 2016).

Dado a isto, de acordo com o IBGE (2018), o município de Rio Brilhante localizado a Sudoeste do Estado de Mato Grosso do Sul, na microrregião da Grande Dourados, com uma área de 3.987, $397 \mathrm{Km}^{2}$, a $151 \mathrm{~km}$ da capital Campo Grande vem se destacando pela sua forte produção de cana-de-açúcar, sendo que no ano de 2017 foi a segunda maior produtora nesta atividade econômica no país, evidenciando a importância deste estudo.

Dessa maneira, uma questão relevante que se coloca é: após todos esses investimentos será que este setor se configura como um polo de crescimento impactando positivamente nos demais setores de modo incisivo? Assim, na busca por uma resposta a essa indagação, estabelecemos como objetivo desta pesquisa analisar, por meio de uma matriz insumo-produto - que permite verificar quais setores possuem 
maior capacidade de gerar impactos na economia — se o setor sucroalcooleiro atua como um polo de crescimento no município de Rio Brilhante-MS.

Para tanto, este estudo está dividido em quatro partes, além desta introdução. Em primeiro lugar, apresentamos os aspectos teóricos da Teoria dos Polos de crescimento de François Perroux que fundamentam o trabalho. Em seguida, detalhamos a metodologia utilizada para o alcance do objetivo estabelecido. Na sequência, explicitamos as análises e discussões de fatos estilizados de Rio Brilhante, vindo após a apresentação dos resultados dessa análise de Matriz Insumo Produto, fechando com as considerações finais e referências utilizadas.

\section{Teoria dos Polos De Crescimento de François Perroux}

François Perroux desenvolveu esta teoria em um cenário profícuo de contextos histórico-econômicos em meados da década de 1950, do século XX na França. O plano de fundo era um embate entre as teorias de desenvolvimento equilibrado e as teorias de desenvolvimento desequilibrado (RIPPEL; LIMA, 2009). Perroux teve seu pensamento embasado nas ideias marshalliana de complexos industriais, bem como apresenta características semelhantes com a teoria schumpeteriana de desenvolvimento econômico (SOUZA, 2005).

É importante pontuar as várias concepções de espaço que François Perroux classifica (MATTE JUNIOR; ALVES, 2017), dividindo-o em: a) espaço homogêneo determinado por um conjunto de aglomerações de indústrias ou empresas que sejam semelhantes em suas estruturas de produção; b) espaço polarizado - nesta perspectiva o espaço econômico forma-se em pontos, focos ou polos que exercem forças de atração e dispersão; c) espaço plano ou programa - caso em que as indústrias estabelecem quais relações irão ter com seus fornecedores ou compradores de insumo-produto (JESUS, SPINOLA, 2015).

Os polos de crescimento possuem uma unidade dominante que pode ser uma firma, um grupo econômico (JESUS, SPINOLA, 2015) uma indústria motriz ou um 
aglomerado de indústrias motrizes, que causa um magnetismo nos objetos ao redor (RIPPEL; LIMA, 2009). Este pensamento ainda é aperfeiçoado quando se apresenta a unidade motriz no lugar da unidade dominante, situação em que a unidade motriz ou um aglomerado delas, exercem efeitos dominantes sobre os demais objetos ligados a ela, podendo estar localizada em um espaço, apenas para exploração, porém seus receptores podem estar localizados em outro espaço. Ela também pode comprar e fornecer insumos-produto de outros locais, além disso pode existir uma dinâmica recíproca entre essas indústrias e empresas. (RIPPEL; LIMA, 2009).

Ainda a respeito da indústria motriz, de acordo com esta teoria os efeitos de uma indústria ou um aglomerado, reverberam na economia por meio dos fluxos, dos preços e das antecipações (LIMA; SIMÕES, 2010). Quanto a isso, pode-se destacar que uma indústria-chave atende ao avanço técnico, assim impulsiona ações sobre o conjunto onde está inserida, motivando economias externas, atraindo para sua região outras indústrias, formando assim os polos (MATTE JUNIOR; ALVES, 2017).

Isto indica que as indústrias motrizes têm papel fundamental sobre outras indústrias e a economia (LIMA; SIMÕES, 2010), fortalecendo as relações industriais nas contratações de serviços de outras empresas, gerando impactos positivos, graças as dinâmicas obtidas nesses processos e promovendo mudanças significativas dentro da região. (MATTE JUNIOR; ALVES, 2017). Pode-se então, encontrar as seguintes características a respeito das indústrias motrizes conforme nos afirma Souza (2005):

[...] cresce a uma taxa superior à média da indústria nacional; (b) possui inúmeras ligações locais de insumo-produto, através das compras e vendas de insumos; (c) apresenta-se como uma atividade inovadora, geralmente de grande dimensão e de estrutura oligopolista; (d) possui grande poder de mercado, influenciando os preços dos produtos e dos insumos e, portanto, a taxa de crescimento das atividades satélites a ela ligadas; (e) produz geralmente para o mercado nacional e, mesmo, para o mercado externo (SOUZA, 2005 p. 89).

Outro ponto quanto a essa temática seriam as inovações técnicas, que segundo Souza (2005) são fundamentais para o desenvolvimento regional. O autor indica que somente a presença das indústrias motrizes não é suficiente para ocorrer $o$ desenvolvimento, pelo contrário "é preciso, antes, que as ações desenvolvimentistas 
partam de baixo para cima, com a criação de pequenas e médias unidades inovadoras, vinculadas com a realidade de cada espaço sub-regional.” (SOUZA, 2005 p. 110). Indica ainda que com essas parcerias, as empresas conseguem reduzir riscos, dividir os custos e ainda ter acesso às novas tecnologias. De acordo com Rippel, Lima (2009), mesmo com essa pura relação com as aglomerações, as técnicas que determinam todos esses fatores dentro dos polos de crescimento, os efeitos técnicos de encadeamento são:

[...] os que dizem respeito à função de produção, ou seja, às relações de compra de insumos e fornecimento de produtos. Os efeitos para trás (fornecimento de insumos), com as indústrias complementares, são geralmente mais importantes que os efeitos para frente [..] (RIPPEL, LIMA, 2009. p. 139).

Milton Santos (2014) também evidencia que as técnicas por muito tempo foram ignoradas por diversos pesquisadores, porém, são fundamentais para o desenvolvimento econômico, sendo importantes para as mais diversas transformações, tanto na construção do espaço quanto nas questões socioculturais. O autor também menciona que as técnicas são universais, entretanto podem mudar de acordo com o lugar e suas necessidades, podendo transformar ou até mesmo realizar um meio geográfico, alterando o modo de vida, a cultura, a produção etc. O autor ainda argumenta que, "as técnicas são um conjunto de meios instrumentais e sociais, com os quais o homem realiza sua vida, produz e, ao mesmo tempo, cria espaço.” (SANTOS, 2014. p.29).

Portanto, de um modo geral, a teoria de Perroux tem os seguintes pilares:

a) o crescimento acontece em lugares ou polos diferentes sendo desequilibrado, não ocorrendo nas mesmas proporções (MATTE JUNIOR, ALVES., 2017); b) O polo de crescimento possui uma forte identificação geográfica, visto que é produto das economias de aglomerações, gerado por um conjunto de ações relacionadas a ligação de insumo-produto, uma vez que os complexos industriais são comandados pelas indústrias motrizes. (SOUZA, 2005); c) existe uma reciprocidade técnica, (RIPPEL, LIMA. 2009) posto que por meio das inovações técnicas é possível formar parcerias e diminuir os riscos do mercado competidor. (SOUZA, 2005); d) as indústrias motrizes têm um dos principais papeis para os efeitos dos polos de desenvolvimento, (LIMA; SIMÕES. 
2010), sendo que elas ocasionam transformações estruturais na sociedade, expandindo o produto e o emprego na região em que está inserida. (SOUZA, 2005). Dessa maneira, é importante verificar se o setor sucroalcooleiro, do município de Rio Brilhante-MS, impacta positivamente outros setores no município e também se fomenta a criação de outras indústrias, com elevada sinergia entre si e também que perpasse pela formação de uma articulação entre esta indústria motriz e as demais.

\section{Metodologia}

A matriz insumo-produto municipal de Rio Brilhante foi estimada a partir do estudo realizado por Frainer et al. (2021), que consiste em estimar a matriz insumoproduto do Estado de Mato Grosso do Sul para o ano de 2015. A estimação da matriz municipal foi realizada por meio do uso da técnica do Quociente Locacional (QL), que se utilizou de dados da Relação Anual de Informações Sociais (RAIS) de 2015, para a estimação/aproximação da produção municipal.

Isto porque, dentre as técnicas desenvolvidas para a regionalização de matrizes de coeficientes técnicos, destaca-se o método do Quociente Locacional (QL), por considerar o ajuste dos coeficientes técnicos a partir da relação entre duas economias, neste caso, economia estadual e municipal e considerar o pressuposto de que um determinado setor da economia da região $j$ mantém a mesma estrutura da economia estadual (BRENE et al. 2011). Assim, o quociente locacional simples para o setor $i$ na região $j$, conforme Miller e Blair (2009), é definido como:

$$
Q L=\frac{E_{j}^{i} / E_{j}}{E_{M S}^{i} / E_{M S}}
$$

onde $E_{j}^{i}$ representa o emprego da atividade industrial $i$ na região $j ; E_{j}$ representa o emprego industrial total na região $j ; E_{M S}^{i}$ representa o emprego da atividade industrial 
do setor $i$ no Mato Grosso do Sul e $E_{M S}$ representa o emprego industrial total no Mato Grosso do Sul.

O quociente locacional simples pode ser visto como uma medida da habilidade da indústria regional $i$ para atender à demanda de outras indústrias e à demanda final da região. Após estimar esses valores, foi possível obter a matriz de coeficientes técnicos regionais a partir do método do quociente locacional. Nos setores em que o QL>1, utilizou-se do mesmo coeficiente estadual e, nos setores em que o QL<1, multiplicou-se o QL calculado pelo seu respectivo coeficiente estadual (WIEBUSCH; FOCHEZATTO, 2011).

Após ter calculado a matriz de coeficientes técnicos regionais, foi possível estimar o valor das transações Intersetoriais do município de Rio Brilhante em 2015. Desta forma, o consumo intermediário foi obtido por meio da multiplicação do coeficiente técnico pelo valor da produção. Após estimados os valores da matriz e, com base na sua matriz de coeficientes técnicos (matriz A), foi possível calcular a matriz inversa de Leontief (matriz B), que permitiu obter os multiplicadores de impactos diretos e indiretos e identificar os setores-chave da economia regional.

A perspectiva de interdependência setorial de uma economia pode ser avaliada por meio de índices que sintetizam as ligações para trás $\left(\mathrm{U}_{\mathrm{j}}\right)$ e para frente $\left(\mathrm{U}_{\mathrm{i}}\right)$ das atividades produtivas, tal como desenvolvido por Rasmussen (1956) e Hirschman (1956). De acordo com Miller e Blair (2009), os valores calculados pelo backward linkage expressam quanto o setor demanda de outros setores da economia, enquanto o forward linkage apresenta o quanto o setor é demandado pelos outros setores. Para Porsse (2002) o índice de forward linkage de um setor $i$ pode ser interpretado como sendo o aumento total da produção de todos os setores da economia quando ocorre o aumento unitário pela demanda final do setor $i$. O índice backward linkage por sua vez, pode ser interpretado como sendo o aumento da produção do setor $i$ quando ocorre um aumento unitário na demanda final da economia. Esses índices são obtidos, respectivamente, pelas seguintes equações: 


$$
\begin{gathered}
U_{j}=\frac{n^{-1} b_{j}}{B^{*}} \\
\mathrm{U}_{i}=\frac{n^{-1} b_{i}}{B^{*}}
\end{gathered}
$$

Onde considera-se $b_{j}$ e $b_{i}$ a soma total das colunas e das linhas da matriz $\mathrm{B}$ e, ainda $\mathrm{B}^{*} \mathrm{o}$ valor médio de todos os elementos dessa matriz.

Esses índices podem ser normalizados tornando-se seu coeficiente médio em relação à média total dos coeficientes. Então, definindo-se a média de cada indicador de ligação e a média total dos coeficientes da matriz de Leontief, como expressas nas equações a baixo:

$$
\begin{aligned}
& \bar{U}=n^{-1} U_{j} \\
& \bar{U}=n^{-2} \sum_{j=1}^{n} \sum_{i=i}^{n} \bar{B}_{i j}
\end{aligned}
$$

os índices de ligações para frente e para trás, normalizados, são obtidos calculando-se, respectivamente:

$$
\begin{array}{r}
U_{i}^{*}=\frac{\bar{U}_{i}}{\bar{U}} \\
U_{j}^{*}=\frac{\bar{U}_{j}}{\bar{U}}
\end{array}
$$


Porsse (2002) destaca que a construção de índices normalizados possibilita uma melhor identificação dos setores-chave, assim, indicadores normalizados com valores superiores à unidade evidenciam setores com comportamento acima da média (setorchave).

A identificação dos setores-chave da economia baseia-se no pressuposto de que algumas atividades têm o potencial de gerar um maior crescimento por meio de suas ligações para trás (backward linkage - BLN) e para frente (forward linkage - FLN), estimulando o restante da economia, o que permite serem utilizadas como ferramenta de planejamento econômico.

Os multiplicadores de impacto podem ser encontrados a partir da matriz de insumo-produto, em que estes resultados derivados consideram as inter-relações setoriais observadas na matriz de coeficientes técnicos. Para Porsse (2002) a construção de multiplicadores contribui para o processo decisório dos policy makers ao definirem as políticas públicas de desenvolvimento regional.

De forma geral, um multiplicador mede o impacto global de variações na demanda final do setor $\mathrm{j}$ sobre uma variável econômica de interesse, ou seja, mede o impacto de um aumento unitário na demanda final de um determinado setor sobre todos os setores que possuem algum grau de ligação com este. (PORSSE, 2002; COSTA et al. 2005). Esse efeito global pode ser decomposto em impactos direto, indireto e efeitorenda, como destaca Feijó et al. (2017):

i) multiplicador direto - mede o impacto de variações na demanda final do jésimo setor, considerando somente as atividades que fornecem insumos diretos a esse setor; ii) multiplicador indireto — mede o impacto de variações na demanda final do jésimo setor, considerando somente as atividades que fornecem insumos indiretos a esse setor; iii) multiplicador efeito-renda - mede o impacto de variações na demanda final do j-ésimo setor, considerando a variação adicional da demanda provocada pelo incremento no nível de rendimentos da economia quando um setor é estimulado.

Neste trabalho, foram construídos multiplicadores para três variáveis macroeconômicas: valor adicionado (VA), emprego (E) e rendimento (R) (remuneração 
do pessoal ocupado). Os multiplicadores totais são encontrados somando-se os três multiplicadores relacionados acima. Tomando-se como exemplo a variável emprego, o multiplicador direto $\left(e_{j}^{D}\right)$ é aquele que mostra o requerimento de emprego por unidade de produto de cada setor, como expresso na Equação 09:

$$
e_{j}^{D}=\frac{E_{j}}{X_{j}}
$$

Onde $E_{j}$ e $X_{j}$ são, respectivamente, o nível de emprego e de produção no setor j.

Os multiplicadores direto e indireto do emprego mostram o impacto de um aumento na demanda final do setor $\mathrm{j}$ sobre o emprego total, dado o encadeamento setorial do modelo aberto de Leontief:

$$
e^{D I}=e^{D} Z
$$

Em que $\mathrm{e}^{\mathrm{DI}}$ representa o vetor do multiplicador direto e indireto do emprego, $\mathrm{e}^{\mathrm{D}}$ representa o vetor dos coeficientes do emprego (emprego por unidade de produto em cada setor) e $\mathrm{Z}$ representa a matriz de Leontief.

O multiplicador total do emprego (direto, indireto e efeito-renda) mostra o impacto de um aumento na demanda final do setor $\mathrm{j}$ sobre o emprego total, dado o encadeamento setorial do modelo fechado:

$$
e^{D I R}=e^{D \bar{Z}}
$$

Em que $\mathrm{e}^{\mathrm{DIR}}$ representa o vetor do multiplicador direto e indireto do emprego. Assim, a partir do multiplicador direto obtido pela equação 06, os multiplicadores indireto $\left(e^{I}\right)$ e efeito-renda $\left(e^{R}\right)$ são deduzidos pelas expressões: 


$$
\begin{gathered}
e^{I}=e^{D I}-e^{D} \\
e^{R}=e^{D I R}-e^{I}-e^{D}=e^{D I R}-e^{D I}
\end{gathered}
$$

Os multiplicadores direto, indireto e efeito-renda para o VA e o rendimento são calculados de forma análoga aos procedimentos descritos acima.

\section{Análises e Discussões de fatos estilizados de Rio Brilhante (MS)}

O consumo de combustíveis fósseis se tornou uma discussão necessária para minimização de impactos ambientais e oportunizou a entrada em pauta da utilização de combustíveis renováveis como uma saída eficaz para o combater à poluição e à agressão ao meio ambiente (PEREIRA, 2007). Além disso, o preço elevado do petróleo na década de 1970 fez surgir o interesse do Brasil em investir na expansão sucroalcooleira por meio da cana-de-açúcar, considerando ainda outra relevância que seria a produção de açúcar que colocava o país em evidência para o mundo (PEREIRA, 2007). Ademais, o desenvolvimento do motor que utiliza o álcool como combustível atua como um elemento de expansão do setor.

Neste cenário, Mato Grosso do Sul se destacou, sendo que suas primeiras indústrias se estabeleceram ao final da década de 1970. Naquela época, isto foi possível graças a uma conjuntura propícia não só da economia mundial, como também estadual, ou seja, o estado de Mato Grosso do Sul possuía uma forte logística favorável aos grandes centros consumidores como São Paulo por exemplo. Outros pontos importantes foram o seu baixo valor da terra, comparado aos outros estados, e o clima que também entrou como outro fator positivo nessa expansão (PEREIRA, 2007).

Não obstante, o estado vinha passando por uma crise na pecuária e na soja, o que fez reduzirem-se os valores nessas duas cadeias, promovendo mais o favorecimento na produção de cana-de-açúcar. Os incentivos fiscais se constituíram em outro aspecto 
importante, tendo em vista que Mato Grosso do Sul fornecia um pacote de benefícios para as indústrias sucroalcooleiras, o que fez alavancar a migração dessas empresas para o estado (PEREIRA, 2007).

Diante dessa situação, no ano de 2018, Mato Grosso do Sul passou a ocupar o $4^{\circ}$ lugar no ranking nacional em produção de cana-de-açúcar, segundo o IBGE, possuindo 19 unidades de usinas sucroalcooleiras. No entanto, recebe maior destaque graças ao município de Rio Brilhante que, até essa data, era o segundo maior produtor de cana-deaçúcar no país (IBGE, 2018). O município possui 3 unidades de usinas sucroalcooleiras localizada em seu território, são elas: Unidade Eldorado do grupo ATVOS, Unidade Passa Tempo e Unidade Rio Brilhante ambas do grupo Biosev (BIOSUL, 2020) conforme o mapa da Figura 1, a seguir.

Figura 1 Mapa de Localização do município de Rio Brilhante (MS) e Região

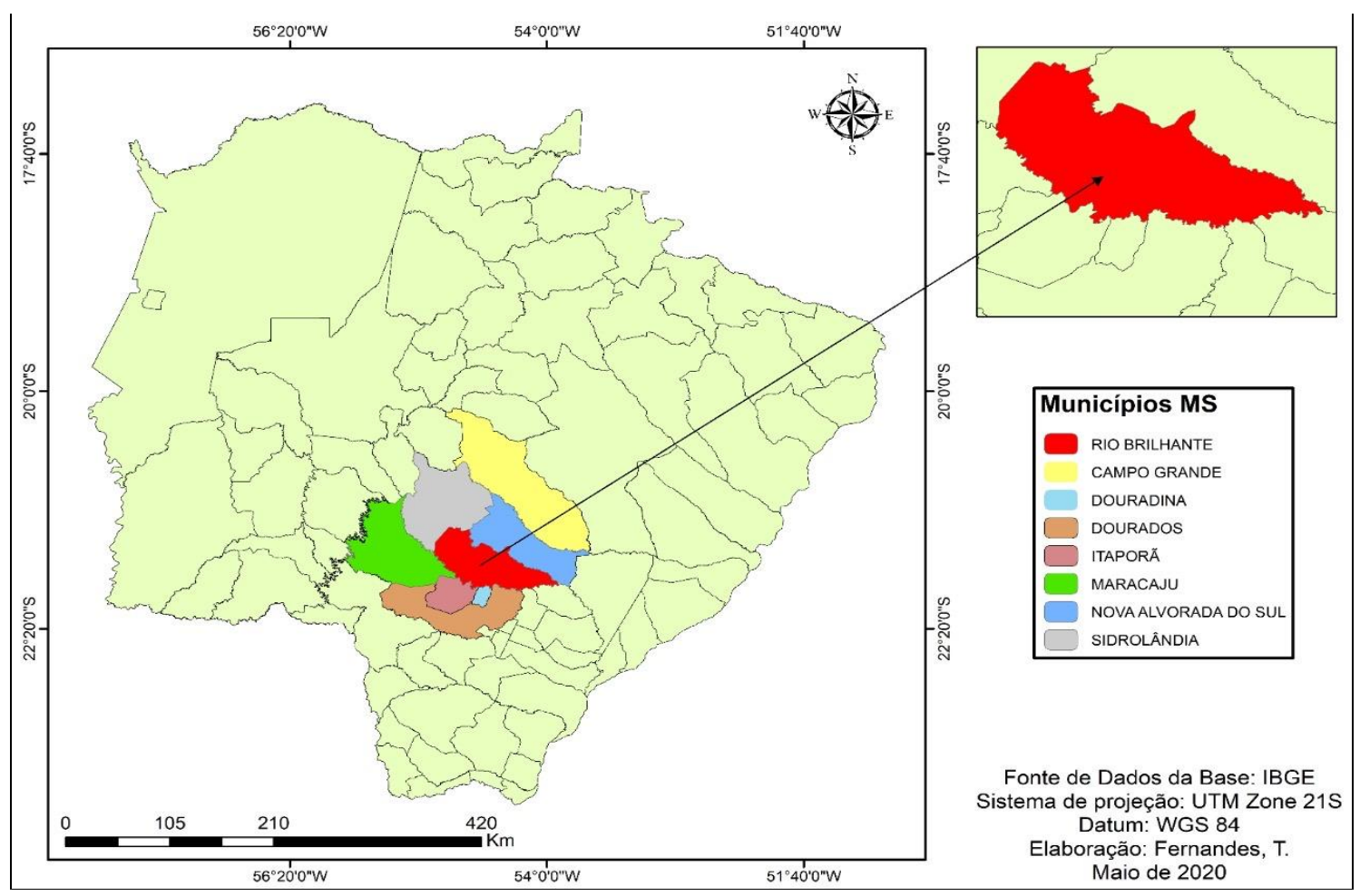

Fonte: Fonte: Elaboração própria baseada em IBGE (2015)

Por meio da figura (1) pode ser observada a localização privilegiada do município de Rio Brilhante, em termos de logística dentro do Estado de MS, 
considerando-se entre outros fatores, o fato de possuir uma proximidade com o Estado de São Paulo. A produtividade de cana-de-açúcar no município e o Produto Interno Bruto constituem-se em um dos primeiros indicadores para a base de articulação com a teoria dos polos de crescimento de Perroux, sendo que o polo de crescimento produz a expansão industrial, sustentando um ritmo crescente em suas ações (RIPPEL; LIMA, 2009). Assim, ao fazermos uma análise na produção de cana-de-açúcar em Rio Brilhante constatamos que os números mostram um crescimento significativo entre os anos de 2006 e 2018, sendo que no ano de 2006 o município produzia 2.167.264 toneladas de cana-de-açúcar e, em 2018, atingiu o número de 7.854 .965 toneladas nessa atividade (IBGE, 2018).

Também no ano de 2006, Rio Brilhante ocupava a posição $29^{\circ}$ no ranking nacional na produção de cana-de-açúcar, dois anos depois, em 2008, passou a ocupar a segunda posição, perdendo apenas para Morro Agudo (SP). Um dos indicativos para esse importante salto, foi o estabelecimento da unidade Eldorado, no município, em março de 2008 (ATVOS, 2017). O gráfico (1) revela a elevação substancial da produção de cana-de-açúcar algo em torno de 300\% no município de Rio Brilhante (MS).

Gráfico 1. Produção (t) de cana-de-açúcar do município de Rio Brilhante (MS) entre os anos de 2006 e 2018.

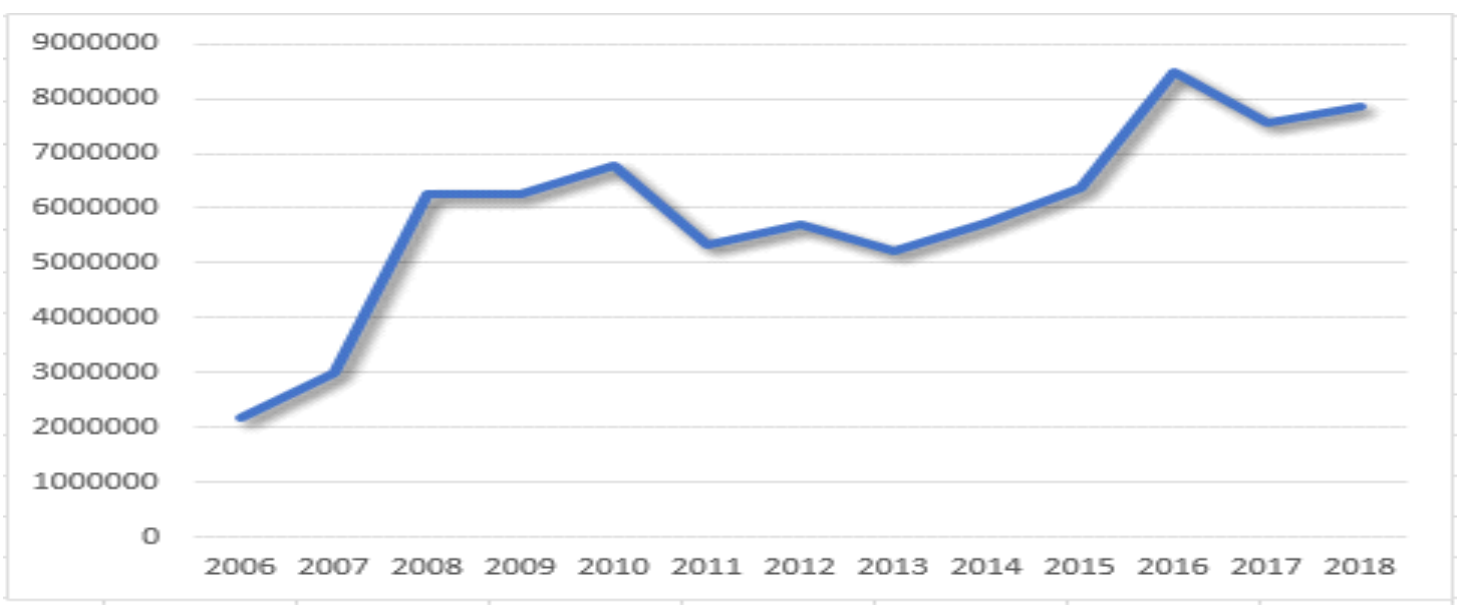

Fonte: IBGE (2018). Elaboração Própria.

Ao considerarmos os valores da produção de cana-de-açúcar em Rio Brilhante, é possível observar um intenso impacto no PIB do município. Nos dados obtidos a partir 
do ano de 2007 foi constatado um número expressivo no aumento do PIB Municipal, PIB Per Capita e PIB Indústria, que pode ser observado nos valores das três variáveis nos anos de 2007 e 2017, explicitados na Tabela 1.

Tabela 1. Produto Interno Bruto de Rio Brilhante (MS) nos anos de 2007 e 2017

Brilhante/MS e Mato Grosso do Sul

\begin{tabular}{l|c|c|c}
\hline Ano & PIB Municipal (R\$) & PIB Per capita (R\$) & PIB Indústria (R\$) \\
\hline 2007 & $656.417,39$ & $24.714,51$ & $75.941,00$ \\
2017 & $2.076 .919,75$ & $57.462,37$ & $499.871,04$ \\
\hline
\end{tabular}

Fonte: IBGE (2017, 2018); SEMADE (2007). Elaboração Própria.

No Gráfico 2, identificam-se as variáveis em (\%), assim, partindo do pressuposto relativo ao ano de 2007 até 2017, o PIB Municipal subiu cerca de 315\%, o PIB Per Capita 231\% e o PIB Indústria 558\%. Nessa análise, as três variáveis tiveram um crescimento exponencial, no decorrer desses 10 anos, no município de Rio Brilhante. Um estudo feito pelo Ministério da Agricultura e Pesquisa Agrícola Municipal do IBGE, levando em consideração as usinas sucroalcooleiras estabelecidas em seu território, divulgou dados em que Rio Brilhante aparece em primeiro lugar no país em PIB Per Capita graças a cultura de cana-de-açúcar, ultrapassando a média nacional de R\$31. 834 (BIOSUL, 2020).

Gráfico 2. Produto Interno Bruto (Municipal, Per capita e Indústria) do município de Rio Brilhante (MS), comparando o crescimento dos respectivos valores (\%) no período de 2007 a 2017

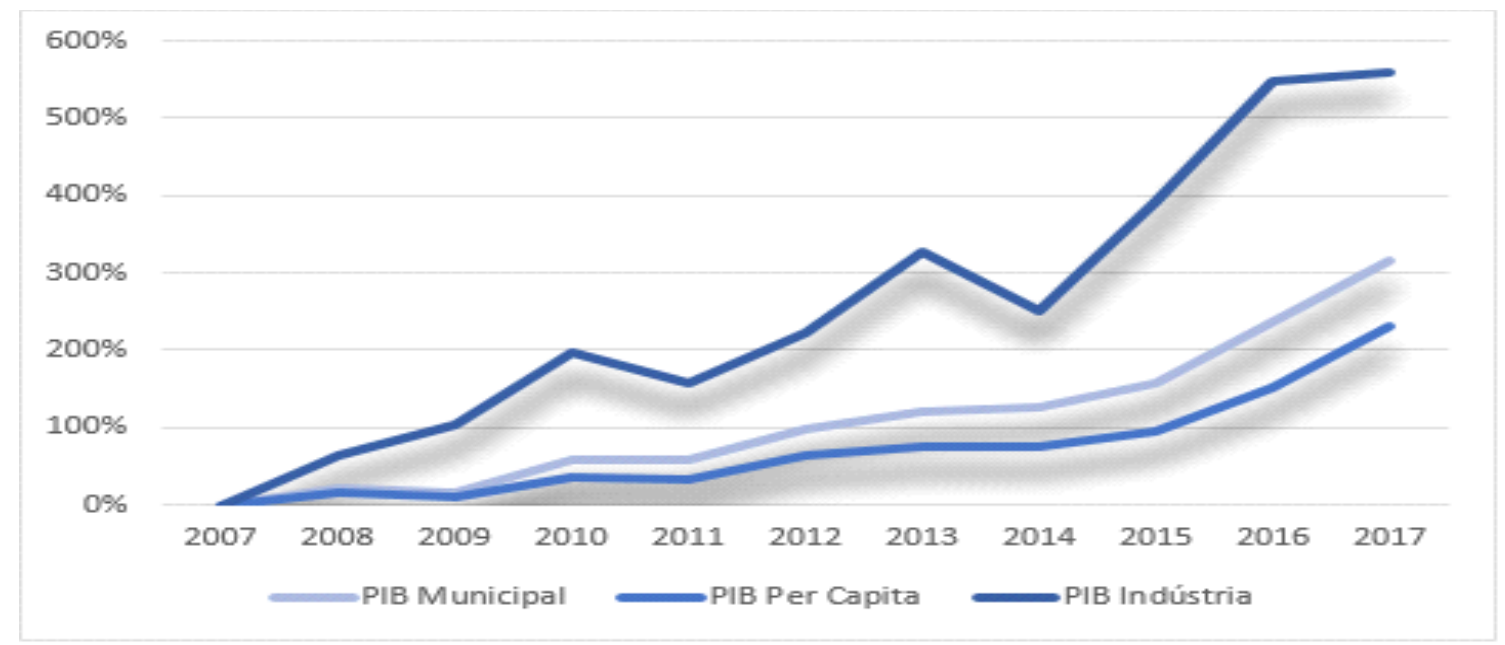

Fonte: IBGE (2017, 2018); SEMADE (2017). Elaboração própria. 
Conforme o Censo no ano de 2010, a população economicamente ativa em Rio Brilhante atingiu uma marca de 16.058 mil pessoas entre homens e mulheres. Neste sentindo, as três usinas sucroalcooleiras estabelecidas no município tiveram papel fundamental na geração de empregos, pois, segundo dados obtidos nos relatórios anuais do grupo ATVOS e Biosev, foi constatado um número significativo de postos de trabalho, somando-se as três unidades juntas (Eldorado, Passa Tempo e Rio Brilhante).

Na safra 2018/2019 só a unidade Eldorado do grupo ATVOS foi responsável por gerar cerca de 4,7 mil empregos, sendo que desse número 3,5 mil são indiretos (ATVOS, 2019). O grupo Biosev que possui duas unidades de usinas sucroalcooleiras no município (Passa Tempo e Rio Brilhante), foi capaz de gerar 2,803 mil postos de trabalho nas duas unidades na safra desse mesmo período. (BIOSEV, 2019). A soma dos respectivos valores dessas três unidades representa mais de 7,5 mil empregos, um número importante para o desenvolvimento não só de Rio Brilhante, como também de toda a região.

Além disso, unidades locais de outras empresas também foram sendo estabelecidas no município. De acordo com dados do site do IBGE (2017), no cadastro central de empresas do ano de 2006, Rio Brilhante possuía cerca de 590 unidades locais, no ano de 2017, passou para cerca de 1, 042 mil unidades locais de empresas cadastradas, gerando um total de 9.823 mil vagas de empregos no município. O salário médio mensal dos trabalhadores do município de Rio Brilhante é em torno de 2,9 salários mínimos (IBGE,2017). Conforme a Tabela 2 é possível observar alguns estabelecimentos industriais que possivelmente foram atraídos até Rio Brilhante sob a influência das três unidades de usinas sucroalcooleiras no município.

Tabela 2 Estabelecimentos Industriais no município de Rio Brilhante (MS) no ano de 2018

\begin{tabular}{l|c}
\hline \multicolumn{1}{c|}{ Atividades } & Quantidades em 2018 \\
\hline Máq. Equipamentos & 7 \\
Metalúrgica - Exc. Máq. Equip - Esquadrias de Metal & 2 \\
Metalurgica - Exc. Máq. Equip - Outros Produtos de Metal & 1 \\
\hline
\end{tabular}
Fonte: SEMAGRO (2019). Elaboração Própria. 
Ao analisarmos, portanto, a tabela (2), é possível observar que existem alguns estabelecimentos industriais no município que possivelmente são fomentados pelo setor sucroalcooleiro, contudo, não é possível constatar uma elevada sinergia e magnitude de indústrias no sentido estrito da análise de Perroux. Assim, o setor parece ser muito importante para o crescimento econômico do município, mas não se pode afirmar que atua como um polo de crescimento, no sentido estrito da teoria de Perroux, sobretudo por não ficar clara a capacidade de fomentar indústrias adicionais com elevada sinergia, magnitude e complementariedades, como no clássico caso da indústria automobilística por exemplo.

\section{Resultados da análise de Matriz Insumo Produto}

\section{Encadeamentos dos setores produtivos}

O índice de ligação possibilita verificar quais setores possuem maior capacidade de gerar impactos na economia, assim como a orientação desses impactos. Por meio da tabela (3) é possível observar os setores que se destacam como setores chave na economia.

Tabela 3 - Índices de ligação normalizados e setores-chave no município de Rio Brilhante/MS e Mato Grosso do Sul

\begin{tabular}{l|ccc|ccc}
\hline \multirow{2}{*}{ Setor } & \multicolumn{3}{c|}{ Rio Brilhante } & \multicolumn{3}{c}{ Mato Grosso do Sul } \\
& BLN & FLN & Orientação & BLN & FLN & Orientação \\
\hline Setor Sucro-energético & 1,07 & 1,03 & Setor chave & 0,95 & 0,75 & Sem ligação \\
Outros Agr-*o+pecuária & 1,00 & 1,00 & Setor chave & 1,20 & 1,21 & Setor chave \\
Agroindústria & 0,99 & 0,99 & Sem ligação & 1,28 & 0,67 & Trás \\
Outras Industria de Transformação & 0,99 & 0,99 & Sem ligação & 1,20 & 0,97 & Trás \\
Construção Civil & 0,99 & 0,99 & Sem ligação & 1,03 & 0,67 & Trás \\
Comércio & 0,99 & 1,01 & Frente & 0,89 & 1,43 & Frente \\
Transporte & 0,99 & 1,00 & Frente & 0,84 & 0,96 & Sem ligação \\
Outros Serviços & 0,99 & 1,00 & Frente & 0,82 & 1,35 & Frente \\
SIUP & 0,99 & 1,00 & Frente & 0,78 & 1,00 & Frente \\
\hline
\end{tabular}

Fonte: Elaboração própria. 
Pela Tabela (3), nota-se que para o município de Rio Brilhante, apenas o "setor Sucroenergético" e "Outros Agropecuária" se destacam como setores chaves, isto é, possuem capacidade de gerar impactos econômicos a jusante e a montante da sua atividade econômica, sendo assim investimentos realizados nestes setores possuem maior spillover na economia municipal. Ainda sobre o município de Rio Brilhante, os setores "Comércio", "Transporte", "Outros serviços" e "SIUP” apresentaram níveis de impactos para a frente, ou seja, os investimentos realizados nestes setores geram impactos econômicos nas atividades a jusante.

Com relação ao estado de Mato Grosso do Sul, apenas o setor "Outros agropecuária" se destaca como setor chave. É possível observar, ainda, a falta de ligação do setor Sucroenergético, fato que corrobora a importância deste setor para a economia do município de Rio Brilhante. Isto poderá ser ainda mais evidenciado por meio da análise dos multiplicadores de impacto setorial na tabela (4).

Tabela 4 - Multiplicadores de impacto setorial no Município de Rio Brilhante/MS

\begin{tabular}{|c|c|c|c|c|c|c|}
\hline \multirow{3}{*}{$\begin{array}{l}\text { Região } \\
\text { Setor }\end{array}$} & \multicolumn{3}{|c|}{ Rio Brilhante } & \multicolumn{3}{|c|}{ Mato Grosso do Sul } \\
\hline & \multicolumn{3}{|c|}{ EMPREGO } & \multicolumn{3}{|c|}{ EMPREGO } \\
\hline & $\begin{array}{l}\text { Efeito } \\
\text { direto }\end{array}$ & $\begin{array}{c}\text { Efeito } \\
\text { Indireto }\end{array}$ & $\begin{array}{c}\text { Efeito } \\
\text { Induzido }\end{array}$ & $\begin{array}{l}\text { Efeito } \\
\text { direto }\end{array}$ & $\begin{array}{c}\text { Efeito } \\
\text { Indireto }\end{array}$ & $\begin{array}{c}\text { Efeito } \\
\text { Induzido }\end{array}$ \\
\hline Setor Sucroenergético & 3.581 & 695 & 1.665 & 3.581 & 6.027 & 27.295 \\
\hline Outros Agropecuária & 14.016 & 138 & 1.251 & 14.016 & 14.899 & 47.355 \\
\hline Agroindústria & 2.043 & 2 & 1.222 & 2.043 & 15.878 & 35.177 \\
\hline $\begin{array}{l}\text { Outras Industria de } \\
\text { Transformação }\end{array}$ & 5.927 & 24 & 1.587 & 5.927 & 12.944 & 31.970 \\
\hline Construção Civil & 12.623 & 9 & 1.809 & 12.623 & 9.882 & 39.427 \\
\hline Comércio & 16.785 & 35 & 3.252 & 16.785 & 6.622 & 40.121 \\
\hline Transporte & 9.008 & 54 & 2.495 & 9.008 & 5.092 & 24.310 \\
\hline Outros Serviços & 12.528 & 8 & 2.327 & 12.528 & 5.080 & 37.263 \\
\hline SIUP & 9.961 & 1 & 5.726 & 9.961 & 4.137 & 25.181 \\
\hline Setor & \multicolumn{3}{|c|}{ VA } & \multicolumn{3}{|c|}{ VA } \\
\hline Setor Sucroenergético & 495.626 & 43.636 & 81.871 & 495.626 & 346.040 & 896.798 \\
\hline Outros Agropecuária & 347.417 & 4.426 & 61.521 & 347.417 & 518.892 & 934.987 \\
\hline Agroindústria & 287.390 & 68 & 60.083 & 287.390 & 570.028 & 874.941 \\
\hline $\begin{array}{l}\text { Outras Industria de } \\
\text { Transformação }\end{array}$ & 173.784 & 977 & 78.024 & 173.784 & 551.518 & 664.137 \\
\hline \multirow{2}{*}{$\begin{array}{l}\text { Construção Civil } \\
\text { Omércio }\end{array}$} & 445.723 & 332 & 88.918 & 445.723 & 400.587 & 857.991 \\
\hline & 603.615 & 1.682 & 159.853 & 603.615 & 314.918 & 847.441 \\
\hline Transporte & 390.231 & 2.732 & 122.635 & 390.231 & 254.800 & 517.700 \\
\hline Outros Serviços & 644.321 & 423 & 114.369 & 644.321 & 247.319 & 996.591 \\
\hline SIUP & 696.843 & 63 & 281.474 & 696.843 & 218.538 & 561.927 \\
\hline
\end{tabular}

Fonte: Elaboração própria. * 1 Milhão de investimentos. 
De forma geral, um multiplicador mede o impacto global de variações na demanda final do setor j sobre uma variável econômica de interesse, ou seja, mede o impacto de um aumento unitário na demanda final de um determinado setor sobre todos os setores que possuem algum grau de ligação com este (PORSSE, 2002; COSTA et al. 2005). Ao analisarmos o impacto do setor Sucroenergético no município de Rio Brilhante, no tocante a emprego, observamos que cada investimento de 1 milhão de unidades monetárias, gera 3.581 empregos diretos, 695 empregos indiretos e 1.665 empregos nos demais setores econômicos. Com relação ao Valor Adicionado (VA), o setor possui capacidade de gerar mais que $\mathrm{R} \$ 495$ mil de forma direta, ou seja, no mesmo setor, $\mathrm{R} \$ 43$ mil de forma indireta, nos setores que comercializam com o setor sucroenergético, e cerca de $\mathrm{R} \$ 81$ mil nos demais setores da economia.

\section{Considerações finais}

A partir do questionamento que nos colocamos sobre o setor sucroalcooleiro da região do município de Rio Brilhante: após todos esses investimentos e produção será que este setor se configura como um polo de crescimento impactando positivamente nos demais setores de modo incisivo?, estabelecemos como objetivo desta pesquisa analisar, por meio de uma matriz insumo-produto, se o setor sucroalcooleiro de Rio Brilhante (MS), se configurava como um polo de crescimento econômico inspirado nas ideias de François Perroux.

A análise da matriz de insumo-produto, possibilitou-nos constatar que o setor "Sucroenergético" e o setor "Outros Agropecuários", se destacam como setores chaves na economia da região, isto é, possuem capacidade de gerar impactos econômicos a jusante e a montante da sua atividade econômica, evidenciando, assim, que investimentos realizados nestes setores possuem maior spillover na economia municipal.

Desse modo, este trabalho encontrou indícios de que o setor agroindustrial sucroalcooleiro no município de Rio Brilhante (MS) atua como um setor chave para o crescimento econômico do município, no entanto, não nos possibilitou afirmar que atua 
como um polo de crescimento. Isso se deve, sobretudo, ao fato de não ficar claro, na pesquisa, a capacidade desse setor de fomentar indústrias adicionais com elevada sinergia - elemento fundamental na teoria de Perroux - como no clássico caso da indústria automobilística, por exemplo.

Dessa perspectiva, esta pesquisa não esgota as necessidades de contínuo estudo, sendo importantes novos métodos e cortes temporais de análise desta relevante temática. Isto, pois é fundamental evidenciar que o crescimento quantitativo de renda, apesar de importante, não implica necessariamente em uma melhora de qualidade de vida da população de um modo geral. Nesse contexto, é fundamental trabalhos que analisem questões de políticas públicas e sociais para auxiliarem neste processo de desafio contínuo de desenvolvimento, sob pena do mesmo ficar restrito a esfera quantitativa financeira.

\section{Referências}

ATVOS. Linha do Tempo. 2017. Disponível em: < https://www.atvos.com/aempresa/linha-do-tempo/>. Acesso em 30 abril 2020.

ATVOS. Relatório Anual, Safra 2018/2019. 2019. Disponível em:<https://www.atvos.com/comunicacao/relatorio-anual/>. Acesso em: 29 abril 2020.

BELLINGIERI, Júlio Cesar. Teorias Do Desenvolvimento Regional E Local: Uma Revisão Bibliográfica. Revista de Desenvolvimento Econômico, Salvador, v. 2, n. 37 , p. 6-34, 2017.

BIOSEV. Relatório de Sustentabilidade, Safra 2018/2019. 2019. Disponível em:< https://www.biosev.com/sustentabilidade/relatorio-de-sustentabilidade/>. Acesso em: 02 abril 2020.

BIOSUL. Associação dos Produtores de Bioenergia de Mato Grosso do Sul. Associadas. 2020. Disponível em: $<$ http://biosulms.com.br/institucional/associadas/ $>$. Acesso em: 27 abril 2020.

BIOSUL. Associação dos Produtores de Bioenergia de Mato Grosso do Sul. Notícias. 2020. Disponível em: $<$ http://biosulms.com.br/municipios-produtores-de-cana-de- 
acucar-em-ms-estao-entre-as-maiores-economias-agricolas-do-pais/>. Acesso em: 04 maio 2020.

BRENE, P. R. A.; SESSO FILHO, U. A.; COSTA, A. J. D.; RANGEL, R. R. Estimativa da matriz de insumo-produto do município de São Bento do Sul no Estado de Santa Catarina. Revista Brasileira de Gestão e Desenvolvimento Regional, [S./.], v. 7, n. 3, p. 250-269, 2011.

BRITTS, Thiago Henrique; DA SILVA, Walter Guedes; ABRITA, Mateus Boldrine. O crescimento canavieiro no município de Rio Brilhante-MS e os impactos ambientais causados pela queima da palha da cana-de-açúcar (2001 a 2010). Revista Cerrados, Montes Claros, v. 14, n. 1, p. 58-76, 2016.

COSTA, E. D.; JÚNIOR, I. T.; BEZERRA, J. F.; MELO, M. V. Matriz de InsumoProduto de Pernambuco para 1999: metodologia de cálculo e subsídios ao planejamento regional. Economia Aplicada, Ribeirão Preto, v.9, n.4, p.595-621, 2005.

COSTA, Rogério Haesbaert da. Regional-Global: Dilemas da Região e da Regionalização na Geografia Contemporânea. Rio de Janeiro, 2010.

DALBERTO, Cassiano Ricardo; STADUTO, Jefferson Andronio Ramundo. Uma análise das economias de aglomeração e seus efeitos sobre os salários industriais brasileiros. Revista de Economia Contemporânea, [S./l.], v. 17, n. 3, 2013.

FEIJÓ, C. A. (Orgs). Contabilidade social: referência atualizada das contas nacionais do Brasil. 5. ed. Rio de Janeiro: Elsevier, 2017.

FRAINER, D. M.; RODRIGUES, W. O. P.; EDUARDO, A. S.; MOREIRA, M. G.. Matriz insumo-produto de Mato Grosso do Sul 2015: construção e análise dos principais indicadores econômicos. Revista de Desenvolvimento Econômico, [S./l.], v. 2, n. 49, 2021 (no prelo).

GOMES, Paulo Cesar da Costa. O Conceito de Região e Sua Discussão. In: CASTRO, Iná, E.; GOMES, Paulo Cesar da C.; CORRÊA, Roberto, L. Geografia: conceitos e temas. Rio de Janeiro. p. 49-76, 1995.

IBGE. Instituto Brasileiro de Geografia e Estatística. Cadastro Central de Empresas. 2018. Disponível em: < https://cidades.ibge.gov.br/brasil/ms/rio-

brilhante/pesquisa/19/29761 >. Acesso em 28 abril 2020.

HIRSCHMAN, A.O. The Strategy of Economic Development. New Haven: Yale University Press. 217p.1958.

IBGE. Instituto Brasileiro de Geografia e Estatística. Cidades. 2018. Disponível em: < https://cidades.ibge.gov.br/brasil/ms/riobrilhante/pesquisa/14/10193?tipo=ranking\&indi

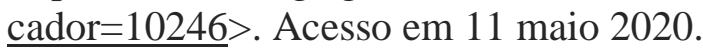


IBGE. Instituto Brasileiro de Geografia e Estatística. Censo, Amostra -Trabalho.

2018. Disponível em:<https://cidades.ibge.gov.br/brasil/ms/rio-

brilhante/pesquisa/23/22957?detalhes=true >. Acesso em: 04 maio 2020.

IBGE. Instituto Brasileiro de Geografia e Estatística. Bases e referencias, bases cartográficas, malhas digitais. 2015. Disponível em: $<$ https://mapas.ibge.gov.br/basese-referenciais/bases-cartograficas/malhas-digitais>. Acesso em: 25 maio 2020.

IBGE. Instituto Brasileiro de Geografia e Estatística. Produção Agrícola Municipal Lavoura Temporária. 2018. Disponível em: <

https://cidades.ibge.gov.br/brasil/ms/rio-brilhante/pesquisa/14/10193 >. Acesso em 30 abril 2020.

IBGE. Instituto Brasileiro de Geografia e Estatística. Produto Interno Bruto dos Municípios. 2017. Disponível em:<https://cidades.ibge.gov.br/brasil/ms/riobrilhante/pesquisa/38/46996 >. Acesso em: 01 maio 2020.

IBGE. Instituto Brasileiro de Geografia e Estatística. Sistema de contas nacionais do Brasil. Rio de Janeiro: 2011.

IPEA, Instituto de Pesquisa Econômica Aplicada. Matriz Insumo-Produto Regional. 2010. Disponível em:

<file:///D:/Rio\%20Brilhante/Termo_de_Referencia_Matriz_Insumo_Produto_Regional. pdf>. Acesso em: 07 Dez. 2019.

JESUS, Josias Alves; SPINOLA, Noelio Dantaslé. Seis Décadas Da Teoria Dos Polos De Crescimento: Revisitando Perroux. Revista de Desenvolvimento Econômico, Salvador, ano XVII, n. 2, p. 935-952, 2015.

MATTE JÚNIOR, Alexandre Aloys; ALVES, Darlã de. A Teoria Dos Polos De Crescimento De Perroux: Uma Revisão Sistemática. Revista de Administração e Negócios da Amazônia, [S./l.], v.9, n.3, p. 103-115, 2017.

MILLER, R.E e BLAIR, P.D. Input-Output Analysis: Foundations and Extensions. Cambridge University Press, 2009.

PEREIRA, Luiz C. et al. Bresser. Desenvolvimento e crise no Brasil. V. 1. Rio de Janeiro: Zahar Editores, 1968.

PEREIRA, Marcelo Castro. A Expansão Sucroalcooleira em Mato Grosso do Sul, Dinâmica e Determinante. 2007. 152 f. Dissertação (Mestrado em Agronegócios) Universidade Federal de Mato Grosso do Sul, Universidade de Brasília, Universidade Federal de Goiás. Campo Grande, 2007.

PORSSE, A. A. Multiplicadores de impacto na economia gaúcha: aplicação do modelo de insumo-produto fechado de Leontief. Porto Alegre: FEE, 2002. 
RIPPEL, Ricardo; LIMA, Jandir Ferreira de. Polos de crescimento econômico: notas sobre o caso do estado do Paraná. Redes. Santa Cruz do Sul. v. 14, n. 1, p. 136-149. 2009.

SANTOS, Milton. Uma Ontologia do Espaço: Noções Fundadoras. In: SANTOS, Milton. A Natureza do Espaço: Técnica e Tempo, Razão e Emoção. 4. ed. 8. reimpr. São Paulo: Edusp, 2014. Cap. 1. p. 29-103

SEMADE. Secretaria de Estado de Meio Ambiente e Desenvolvimento Econômico. BdEweb - Base de Dados do Estado. 2017. Disponível em: <http://bdeweb.semade.ms.gov.br/bdeweb/ >. Acesso em: 01 maio 2020.

SEMAGRO. Secretaria de Estado de Meio Ambiente e Desenvolvimento Econômico, Produção e Agricultura Familiar. Comissão Mista Brasil-Paraguai aprova resultado da licitação da ponte sobre o Rio Paraguai. 2020. Disponível em:< https://www.semagro.ms.gov.br/comissao-mista-brasil-paraguai-aprova-resultado-da-

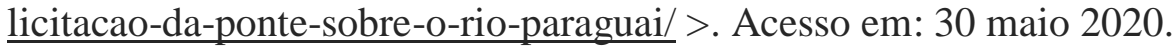

SEMAGRO. Secretaria de Estado de Meio Ambiente e Desenvolvimento Econômico, Produção e Agricultura Familiar. Dados Estatísticos dos Municípios de MS. 2019. Disponível em:< http://www.semagro.ms.gov.br/perfis-socioeconomicos-do-ms-emunicipios/ >. Acesso em: 04 maio 2020.

SIMÕES, Rodrigo Ferreira; LIMA, Ana Carolina da Cruz. Teorias do desenvolvimento regional e suas implicações de política econômica no pós-guerra: o caso do Brasil. texto para discussão $\mathbf{N}^{\circ}$ 358, Cedeplar, Belo Horizonte, 2009.

SOUZA, Nali de Jesus de. Teoria Dos Pólos, Regiões Inteligentes E Sistemas Regionais De Inovação. Análise. Porto Alegre, v. 16, n. 1, p. 87-112, 2005.

WIEBUSCH, F. C.; FOCHEZATTO, A. Um método simples de obtenção de matrizes regionais de insumo-produto: aplicação ao Vale do Taquari. In. ALVIN, A. M.; SOUZA, O. T.; CALANDRO, M. L.(Orgs). Os desafios do desenvolvimento: tendências e perspectivas para a economia gaúcha. Porto Alegre: EDIPUCRS, 2011. 538P.

Tatiane Aparecida Dreger De Souza Fernandes - Graduanda em Geografia (Licenciatura) pela Universidade Estadual de Mato Grosso do Sul (UEMS).

Endereço: Av. Dom Antônio Barbosa, 4155 - Vila Santo Amaro, Campo Grande - MS, 79115-898. 
Mateus Boldrine Abrita - É Graduado em Ciências Econômicas pela Universidade Federal de Mato Grosso do Sul (UFMS), Mestre em Ciências Econômicas pela Universidade Estadual de Maringá (UEM) e Doutor em Economia pela Universidade Federal do Rio Grande do Sul (UFRGS). Atualmente é Professor da Universidade Estadual de Mato Grosso do Sul (UEMS) unidade Campo Grande, atuando nos cursos de Geografia Licenciatura e Bacharelado.

Endereço: Av. Dom Antônio Barbosa, 4155 - Vila Santo Amaro, Campo Grande - MS, 79115-898.

Wesley Osvaldo Pradella Rodrigues - É Graduado em Administração de Empresas pela Universidade para o Desenvolvimento do Estado e da Região do Pantanal (UNIDERP), Mestre em Agronegócios pela Universidade Federal da Grande Dourados (UFGD) e Doutor em Meio Ambiente e Desenvolvimento Regional pela Universidade Anhanguera (UNIDERP). Atualemnte é Professor da Universidade Federal de Mato Grosso do Sul (UFMS), Câmpus Naviraí, no curso de Administração.

Endereço: Rodovia MS 141, Km 04, Saída para Ivinhema - Naviraí - MS.

Artigo recebido em: 25 de fevereiro de 2021. Artigo aceito em: 16 de maio de 2021. Artigo publicado em: 01 de agosto de 2021. 